\title{
Long lasting luminescence in TbAG:Ce phosphor
}

\author{
N.D.Meshram ${ }^{1 *}$, P.J.Yadav ${ }^{2}$, C.P.Joshi ${ }^{3}$ and S.V.Moharil ${ }^{4}$ \\ ${ }^{1}$ Department of Electronics, Shri. Mathuradas Mohota College of Science, Sakkardara Square, \\ Nagpur-440009, India. \\ ${ }^{2}$ Department of Electronics, RTM Nagpur University Campus, Nagpur-440002, India. \\ ${ }^{3}$ Department of Physics, Ramdeobaba College of Engineering \& Management, Katol road, \\ Gittikhadan, Nagpur, India. \\ ${ }^{4}$ Department of Physics, RTM Nagpur University Campus, Nagpur-440002, India. \\ *Email: meshramnileshsd@gmail.com
}

$\mathrm{Tb}_{3} \mathrm{Al}_{5} \mathrm{O}_{12}$ (TAG) terbium-aluminum garnet is used in optical filters based on the Faraday effect [1] and in luminescence converters of blue LED radiation to obtain light sources with a white emission spectrum [2]. An intense $5 \mathrm{~d}-$ 4f photoluminescence of $\mathrm{Ce}^{3+}$ on the $\mathrm{Tb}^{3+}$ site in $\mathrm{Tb}_{3} \mathrm{Al}_{5} \mathrm{O}_{12}$ (TAG) powder has been reported by Kummer et al. [3], $\mathrm{Tb}_{3} \mathrm{Al}_{5} \mathrm{O}_{12}$ activated with Ce phosphors were prepared by combustion synthesis. Reagent grade rare earth oxides/carbonates were converted to the corresponding nitrates by dissolving in nitric acid. The nitrates were dried by prolonged, gentle warming. A china dish containing the paste was inserted in a furnace preheated to $500^{\circ} \mathrm{C}$. Within minutes the paste foamed and a flame was produced which lasted for several seconds.

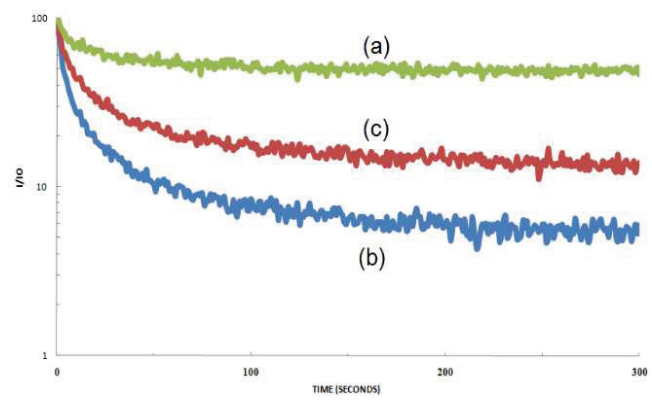

Figure 1: Long Lasting luminescence graph of $\mathrm{Tb}_{3} \mathrm{Al}_{5} \mathrm{O}_{12}$ :Ce phosphor

Green LL is observed in $\mathrm{Ce}$ doped $\mathrm{Tb}_{3} \mathrm{Al}_{5} \mathrm{O}_{12}$ : $\mathrm{Ce}$ garnet phosphors. LL is well correlated with $\mathrm{Ce}^{3+}$ emission and a peak around $140^{\circ} \mathrm{C}$ in the TL glow curve. This can be well explained by referring Figure 1 and figure 2. In comparison with the commercial phosphor YAG, the $\mathrm{Tb}_{3} \mathrm{Al}_{5} \mathrm{O}_{12}$ : $\mathrm{Ce}$ (TAG) is more stable and shows more intense TL properties, this phosphor can be used for dosimetric detections and measurements.

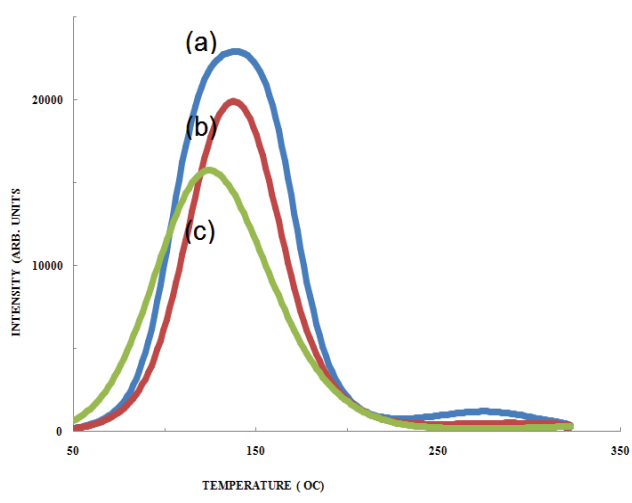

Figure 2: TL glow curve graph of $\mathrm{Tb}_{3} \mathrm{Al}_{5} \mathrm{O}_{12}$ : $\mathrm{Ce}$ phosphor

\section{References}

1. V. I. Chani, Mater. Sci. Eng. B 75 (2000) 53

2.HongdeLuo, et.allJ. Am. Ceram. Soc., 95 (2012) 3582

3. F. Kummer, Intern. Patent Appl., WO 01/08452 (2001) 